\title{
The Brief Assessment of Cognition in Affective Disorders Battery as a diagnostic tool of cognitive deficits in alcohol addicts
}

Berezina, A.A. (1,2), Gvozdetckii, A.N. (1), Klimanova, S.G. (1,2), Trusova, A.V. (1,2)

1 - Saint-Petersburg State University, 2 - V.M. Bekhterev National Research Medical Center for Psychiatry and Neurology

\section{Background}

Studies show various cognitive deficits in alcohol addicts, which can be subdivided into three types: 1) executive deficits; 2) disproportion between verbal and nonverbal processes; 3) general cognitive dysfunction (Bernardin et al., 2014; Stavro et al., 2013).

Some authors show executive deficits to lead in the cognitive deficits structure in alcohol addicts (Ihara, Berrios, London, 2000).

However there is in no specialised and adopted in Russia instrument assessing specialities of cognitive dysfunction in alcohol use disorder. One of the possible variants is he Brief Assessment of Cognition in Affective Disorders scale (Keefe et al., 2014). The scale is adopted in Russia (Yanushko et al., 2016), and is intended both at assessment of general cognition and at evaluation of executive functions, which correspond to the goals of cognitive assessment in addicts.

The aim of the study

To evaluate usability of The Brief Assessment of Cognition in Affective Disorders scale

(BAC-A) in the revealing of different cognitive deficits in alcohol addicts.

\section{Methods}

- The Brief Assessment of Cognition in Affective Disorders Battery

- Structured interview revealing clinical parameters in patients

Sample

- 118 subjects with alcohol use disorder

- undergoing detoxification treatment in V.M Bekhterev National Research Medical Center for Psychiatry and Neurology

- 32 females, 86 males

- Age 42,19 $(8,17)(\mathrm{M}(\sigma)$

- Duration of disease $10,86(7,63)(\mathrm{M}(\sigma)$

- $69,5 \%$ of patients with hereditary predisposition

\section{Results}

Patients show deficits in all domains except of learning of emotional and neutral worlds (in comparison with normative level $(T=40)$. Cognitive functions structure included working memory and planning and decision making ability influencing general level of cognitive functioning.

\section{Cognitive functions structure} (RMSEA=0,055)

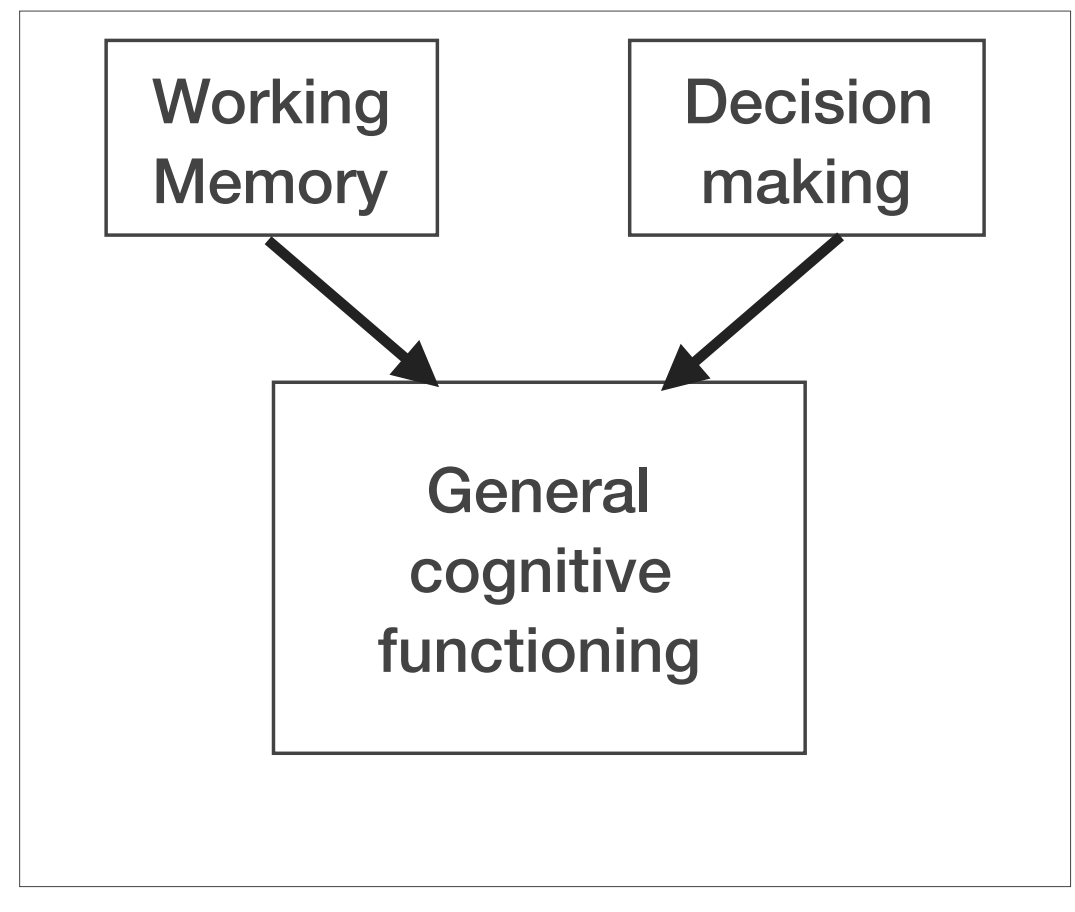

The model of relationships between clinical parameters included heredity, duration of disease, working memory and general cognitive functioning parameters. Heredity and duration of disease influenced on genera cognitive functioning and the relation was mediated by working memory parameter.

\section{Legend \\ $x^{* * *}-p<0,001$ \\ $x^{* *}-p<0,01$}

\section{independent variable}

The reported study was refunded by RFBR project number 16-06-01043

Comparison of BAC-A data in patients with AUD with normative value $(T=40)$
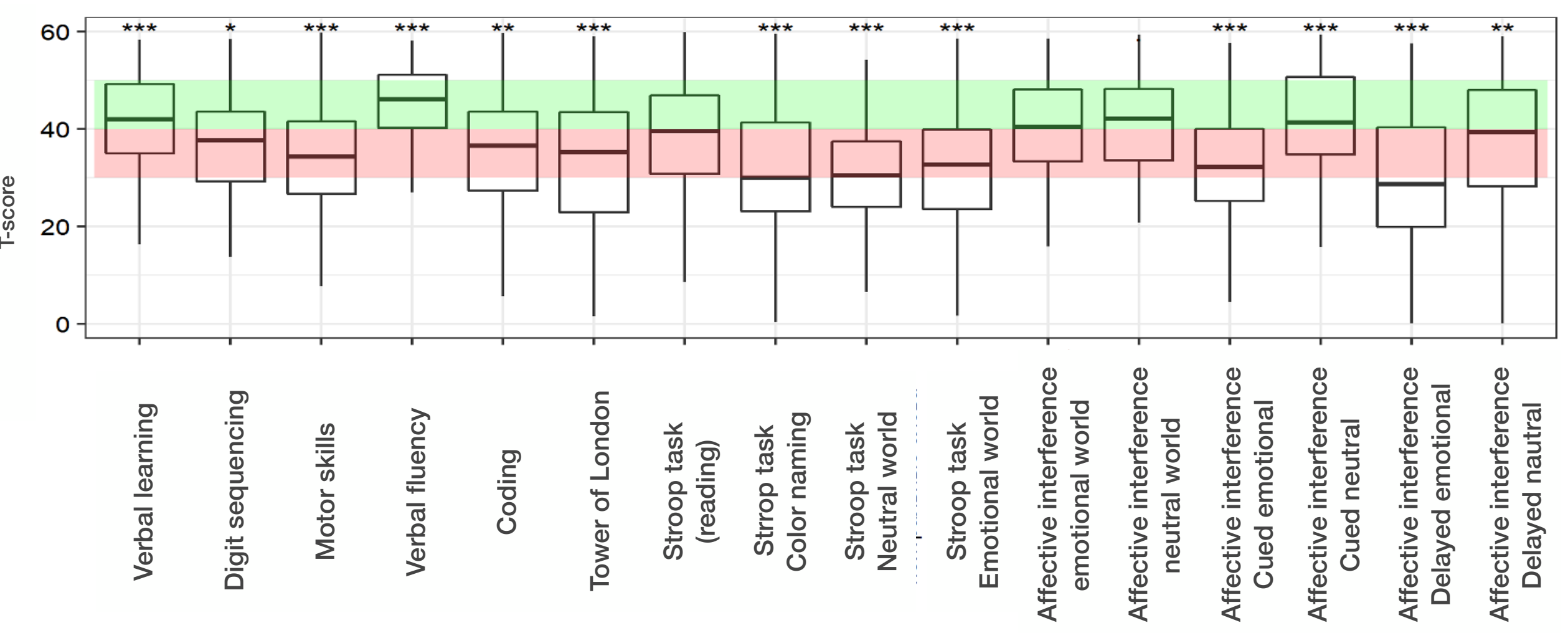

Relationship between clinical and cognitive parameters (RMSEA=0,000)

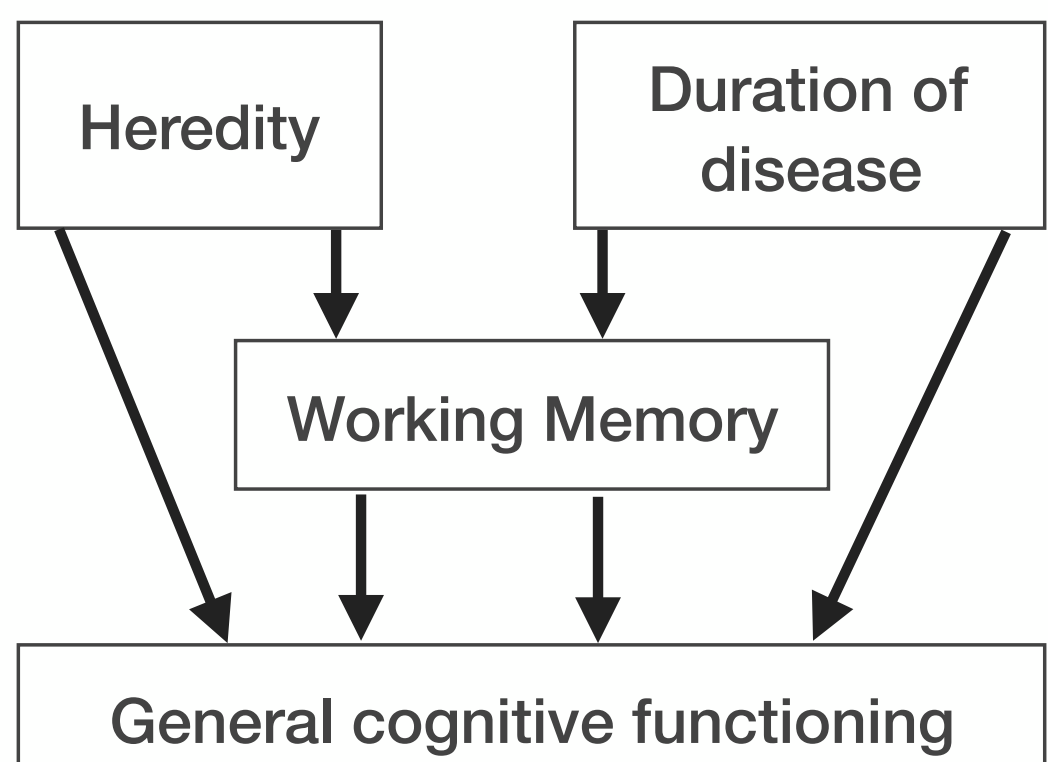

\section{Conclusion}

1. The BAC-A reveals specific cognitive deficits in alcohol addict.

2. The BAC-A shows appropriate structure of cognitive dysfunction in AUD with prevailing of executive functions.
References

Bernardin, F., Maheut-Bosser, A., \& Paille, F. (2014). Cognitive Impairments in AlcoholDependent Subjects. Frontiers in Psychiatry, 5.

Ihara, H., Berrios, G. E., \& London, M. (2000). Group and case study of the dysexecutive syndrome in alcoholism without amnesia. Journal of Neurology, Neurosurgery, and Psychiatry, 68(6), 731-737.

Keefe, R. S. E., Fox, K. H., Davis, V. G., Kennel, C., Walker, T. M., Burdick, K. E., \& Harvey, P. D. (2014). The Brief Assessment of Cognition In Affective Disorders (BACA):performance of patients with bipolar depression and healthy controls. Journal of Affective Disorders, 166, 86-92.

Stavro, K., Pelletier, J., \& Potvin, S. (2013) Widespread and sustained cognitive deficits in alcoholism: a meta-analysis. Addiction Biology, 18(2), 203-213.

Yanushko, M.G.., Shamanina, M.V., Aristova, T.A., Keefe, R., Ivanov, M.V., Tolmacheva, M. (2015) Standartization of the scale «Brief assessment of cognition in patients with affective disorders» (BAC-A) on the basis of normative data for Russian population. Russian journal of psychiatry, 2 